\title{
From BAM to BEM, a personal journey through EJTM and Padua Muscle Days
}

\author{
Ugo Carraro $^{1 *}$ \\ ${ }^{1}$ IRCCS Fondazione Ospedale San Camillo, Venezia, Italy
}

\begin{abstract}
As a young researcher I had the only option to work on molecular myology at the University of Padova, Italy. This took me to develop special expertise in muscle proteins analyses at molecular levels. Introduced to the study of muscle denervation/reinnervation I started a research project on long term denervated muscle, whose management continues to be my primary interest. On the way, I started a series of rehabilitation conferences in Terme Euganee, Padua, Italy and founded a dedicated journal to basic research and eventual application of muscle studies, i.e., "Basic and Applied Myology" (BAM). From 2010 the journal changed name to "European Journal of Translational Myology" (EJTM), whose contents are limited to Myology, though their implications are of foremost importance in several neurological disorders, in aging and in oncology. Thus, I was attracted by, and I am proud to contribute to "Biology, Engineering and Medicine" (BEM) that extends its contents to the full range of medical problems and eventual solutions by means of interactions of biology and technology to manage medical problems.
\end{abstract}

As a young researcher I had the only option to work on molecular myology at the University of Padova, Italy. This took me to develop special expertise in muscle proteins analyses at molecular levels that at that time were based on gel electrophoresis and then bi-dimensional gel electrophoresis. Introduced to the study of muscle denervation/ reinnervation I started a research project on long term denervated muscle that still is my primary interest and took me from Dynamic Cardiomyoplasty to muscle apoptosis, Spinal cord injury-related muscle denervation and their eventual managements by electrical stimulation of denervated muscles. On the way, I started a series of rehabilitation conferences in Terme Euganee, Padua, Italy and founded a dedicated journal to basic research and eventual application of muscle studies, i.e., Basic and Applied Myology (BAM). From 2010 the journal changed name to European Journal of Translational Myology (EJTM), whose contents are limited to Myology, though their implications are of foremost importance in several neurological disorders, cancer cachexia and aging. Thus, I was attracted by the journal Biology, Engineering and Medicine (BEM) that extends its contents to the full range of medical problems and eventual solutions by means of interaction of biology and technology to manage medical problems.

The collection of abstracts of the 2017 Spring Padua Muscle Days (2017SpPMD), that were held March 23 to 25 in Montegrotto, Euganei Hills (Padova) Italy, opens the second Issue of the European Journal of Translational Myology (EJTM) 27, 2017 [1]. The First Padua Myology Meeting was titled Abano Terme Rehabilitation Conference, and focused, as the title suggests, on injury prevention combined with rehabilitation. The meetings commenced at a time during which implantable neuromuscular electrical stimulators seemed to be a very attractive potential solution for spinal cord injury sequelae. Initially, meetings were held every three years, but because of the pressure from "Myology Friends", they became annual and eventual bi-annual events (Spring and Autumn Meetings were held for several years). Muscle health and related injury prevention and rehabilitation are still a focal point; however, topics of the Padua Meetings have also encompassed cardiac muscle work, including Dynamic Cardiomyoplasty which was based on the fascinating idea of supporting a weak heart by wrapping it within the latissimus dorsi skeletal muscle which is made to synchronously squeeze the ventricles by sensing and responding to the heart beat through electrical stimulation of its intramuscular nerve branches [2]. In 1991 a new journal titled Basic and Applied Myology (BAM), retitled European Journal of Translational Myology (EJTM) in 2010, began publishing original articles concerning biomedical research in myology and tentative applications of new knowledge to prevent, cure and rehabilitate mobility impaired young and old persons. Electrical stimulation of denervated muscle became the driving topic of the PaduaMuscleDays and this both nurtured and allowed to implement the EU Project RISE (Use of electrical stimulation to restore standing in paraplegics with long-term denervated degenerated muscles) (QLG5CT-2001-02191) [3-8].

Functional Electrical Stimulation was (and is), indeed, one of the main topic of the collective sessions, but in every event other issues related to muscle biology, imaging, function, disease and treatments were discussed. Many important science topics were covered and sometime introduced. An important example includes the first world meeting in 1995 at Abano Terme (Padova) Italy which attracted the attention of molecular and cellular researchers and clinicians to the role of apoptosis in development, damage and repair of skeletal muscle and heart [9]. This has become a very important research topic during the subsequent years [10]. So given this history, it will not be a surprise to find that the Collection of Abstracts of the 2017 Spring PaduaMuscleDays covers a new discovery on the mechanisms of $\mathrm{Ca}^{2+}$ handling at ultrastructural level and spans to cover work on

Correspondence to: Ugo Carraro, IRCCS Fondazione Ospedale San Camillo, Venezia, Italy; E-mail: ugo.carraro@ospedalesancamillo.net

Key words: BAM, BEM, EJTM, Translational Myology, PaduaMuscleDays, Biology, Engineering and Medicine

Received: April 19, 2017; Accepted: April 24, 2017; Published: April 29, 2017 
take-home rehabilitation strategies to rejuvenate older old humans [11-23]. Additional information is in the 2017SpPMD PROMO at: https://www.youtube.com/watch? $\mathrm{v}=\mathrm{NdbbeQFi9z8 \& t=4 \textrm {s }}$ and in the new Youtube Channel: https://www.youtube.com/channel/ UCshXMdDxpuOKa7eCWMBRqLg/videos?sort=dd\&view=0\&shelf_ $\mathrm{id}=0$ The conference is, indeed, expanding beyond the boundaries of time and walls to include the internet and social media. While personal contacts that young researchers may have with experienced senior investigators is the main reason to organize the PaduaMuscleDays, those new opportunities for scientific interaction may be a second reason for experts in the many facets of Translational Myology to attend, offering easy-to-obtain valuable information to other investigators in both person and through cyberspace. The Youtube Channel is, and will be even more in the near future, filled with Promos of future meetings and with videos from the presentations.

Near future events will be the 3rd Padua Myology Seminar for general audience, in particular of old persons, to be held late September in Padua's Accademia Galileiana di Scienze, Lettere ed Arti, that holds its meetings surrounded by the frescos of the Gothic painter Guariento, who was the last before Giotto introduced the Italian Renaissance Style painting in the Scrovegni Chapel in Padua.

The 2018 Spring PaduaMuscleDays will be held in Euganei Hills and Padua (Italy), March 14-16, 2018. The driving event being the Symposium: "Giovanni Salviati Memorial" which will be held to honor a beloved friend and excellent scientist 20 years after his death. Suggestions of topics and speakers for other Workshops of the 2018 Spring Padua Muscle Days are welcomed.

\section{References}

1. Editors (2017) Abstracts of the 2017 Spring Padua Muscle Days, Padua, Italy. Eur J Transl Myol 27: 7X-11Y.

2. Carpentier A, Chachques JC (1985) Myocardial substitution with a stimulated skeletal muscle: first successful clinical case. Lancet 1: 1267. [Crossref]

3. Kern H, Boncompagni S, Rossini K, Mayr W, Zanin ME et al. (2004) Long-term denervation in humans causes degeneration of both contractile and excitationcontraction coupling apparatus, wich is reversibile by functional electrical stimulation (FES). A role for myofiber regeneration? J Neuropathol Exp Neurol 63: 919-931. [Crossref]

4. Boncompagni S, Kern H, Rossini K, Hofer C, Mayr W et al. (2007) Structural differentiation of skeletal muscle fibers in the absence of innervation in humans. Proc Natl Acad Sci U S A 104: 19339-19344. [Crossref]

5. Kern H, Carraro U, Adami N, Biral D, Hofer C et al. (2010) Home-based functional electrical stimulation rescues permanently denervated muscles in paraplegic patients with complete lower motor neuron lesion. Neurorehabil Neural Repair 24: 709-721. [Crossref]

6. Gargiulo P, Reynisson PJ, Helgason B, Kern H, Mayr W et al. (2011) Muscle, tendons, and bone: structural changes during denervation and FES treatment. Neurol Res 33: 750-758. [Crossref]
7. Carraro U, Kern H, Gava P, Hofer C, Loefler S et al. (2015) Biology of Muscle Atrophy and of its Recovery by FES in Aging and Mobility Impairments: Roots and ByProducts. Eur J Transl Myol 25: 221-230. [Crossref]

8. Kern H, Hofer C, Loefler S, Zampieri S, Gargiulo P et al. (2017) Atrophy, ultrastructural disorders, severe atrophy and degeneration of denervated human muscle in SCI and Aging. Implications for their recovery by Functional Electrical Stimulation, updated 2017. Neurol Res 13: 1-7. [Crossref]

9. Carraro U, Franceschi C (1997) Apoptosis of skeletal and cardiac muscles and physical exercise. Aging (Milano) 9: 19-34. [Crossref]

10. Phaneuf S, Leeuwenburgh C (2001) Apoptosis and exercise. Med Sci Sports Exerc 33: 393-396. [Crossref]

11. Carraro U, Gava K, Baba A, Piccione F, Marcante A (2016) Fighting muscle weakness in advanced aging by take-home strategies: Safe anti-aging full-body in-bed gym and functional electrical stimulation (FES) for mobility compromised elderly people. Biol Eng Med 1: 1-4.

12. Pette d, Vrbová G (2017) The contribution of neuromuscular stimulation in elucidating muscle plasticity revisited. Eur J Transl Myol 27: 33-39. [Crossref]

13. Pigna E, Greco E, Morozzi G, Grottelli S, Rotini A et al. (2017) Denervation does not Induce Muscle Atrophy Through Oxidative Stress. Eur J Transl Myol 27: 6406. [Crossref]

14. Gentil P, Barbosa de Lira C, Paoli A, Dos Santos JAB, da Silva RDT et al. (2017) Nutrition, pharmacological and training strategies adopted by six bodybuilders: case report and critical review. Eur J Transl Myol 27: 51-66. [Crossref]

15. Coletti D, Adamo S, Moresi V. (2017) Of faeces and sweat. How much a mouse is willing to run: having a hard time measuring spontaneous physical activity in different mouse sub-strains. Eur J Transl Myol 27: 67-70. [Crossref]

16. Power GA, Dalton BH, Gilmore KJ, Allen MD, Doherty TJ et al. (2017) Maintaining Motor Units into Old Age: Running the Final Common Pathway. Eur J Transl Myol 27: 6597. [Crossref]

17. Pond AL, Anderson LB, Cobb BA, et al. (2017) The ERG1 Potassium Channel is detected in human skeletal muscle with greater abundance in cachectic patients. Eur J Transl Myol 27: 94.

18. Pond A, Marcante A, Zanato R, Martino L, Stramare R et al. (2014) History, Mechanisms and Clinical Value of Fibrillation Analyses in Muscle Denervation and Reinnervation by Single Fiber Electromyography and Dynamic Echomyography. Eur $J$ Transl Myol 24: 3297. [Crossref]

19. Edmunds KJ, Árnadóttir Í, Gíslason MK, Carraro U and Gargiulo P (2016) Nonlinear Trimodal Regression Analysis of Radiodensitometric Distributions to Quantify Sarcopenic and Sequelae Muscle Degeneration. Comput Math Methods Med: 8932950 [Crossref]

20. Edmunds KJ, Gíslason MK, Arnadottir ID, Marcante A, Piccione F et al. (2016) Quantitative Computed Tomography and Image Analysis for Advanced Muscle Assessment. Eur J Transl Myol 26: 6015. [Crossref]

21. Helgason T, Arnason B, Gudmundsdottir V, et al. (2017) Comparing somatosensory evoked potentials resulting from transcutaneous spinal cord stimulation (tSCS) and tibial nerve stimulation in healthy and CP subjects. Eur J Transl Myol 27: 104.

22. Helgason T, Gunnlaugsdottir KI (2015) Application of Acoustic-Electric Interaction for Neuro-Muscular Activity Mapping: A Review. Eur J Transl Myol 24: 4745. [Crossref]

23. Carotenuto F, Costa A, Albertini MC, Rocchi MB, Rudov A et al. (2016) Dietary Flaxseed Mitigates Impaired Skeletal Muscle Regeneration: in Vivo, in Vitro and in Silico Studies. Int J Med Sci 13: 206-219. [Crossref]

Copyright: (C2017 Carraro U. This is an open-access article distributed under the terms of the Creative Commons Attribution License, which permits unrestricted use, distribution, and reproduction in any medium, provided the original author and source are credited. 